\title{
СПЕКТР НЕВРОЛОГИЧЕСКИХ РАССТРОЙСТВ ПРИ НЕКОТОРЫХ РЕВМАТИЧЕСКИХ ЗАБОЛЕВАНИЯХ
}

${ }^{1}$ Касумова Ф.Н.*, ${ }^{2}$ Алиев Р.Р., ${ }^{1}$ Мамедова Р.Н.

Азербайджанский Государственный Институт Усовершенствования Врачей имени А. Алиева,

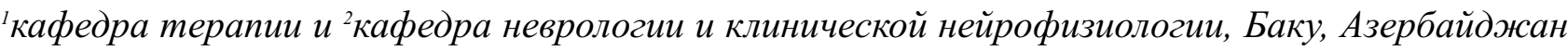

Ревматические заболевания (Р3) - это группа иммуновоспалительных болезней, характеризующихся полиорганным поражением. Большинство Р3 имеет системный характер поражения, причем, у большей части больных в патологический процесс вовлекается нервная система. Поражение нервной системы при Р3 проявляется разнообразными симптомами и синдромами со стороны центральной и периферической нервной системы. Широкий диапазон неврологической патологии при различных нозологических формах Р3, диктует необходимость более углубленного изучения цереброваскулярных и других неврологических нарушений при данной группе заболеваний.

Ключевые слова: ревматические заболевания, неврологическая патология, поражение центральной и периферической нервной системы.

$\mathbf{B}$

последние десятилетия ревматические болезни привлекают к себе все более пристальное внимание вследствие их широкого распространения. Довольно часто ревматические заболевания (Р3) приводят к временной и стойкой утрате трудоспособности, а также сопровождаются высокими показателями смертности [1].

Ревматические болезни - относятся к группе системных иммуновоспалительных болезней, характеризующихся полиорганным поражением. Большинству Р3 свойственно системность поражения с вовлечением в патологический процесс различных органов и систем, причем у большей части больных в патологический процесс вовлекается нервная система [2]. К числу наиболее сложных клинических проблем, с которыми сталкиваются ревматологи, относятся точная диагностика и правильное лечение неврологических нарушений при РЗ. Широкий диапазон неврологических синдромов при аутоиммунных системных заболеваниях объясняется общностью и взаимосвязью нервной и иммунной систем, сходством их структур и функций [2].

По данным различных авторов, частота поражений нервной системы при РЗ колеблется от $40 \%$ до 70\% и выше. Цереброваскулярная патология была доминирующей в клинической картине таких болезней, как системная красная волчанка, антифосфолипидный синдром, болезнь Такаясу, болезнь Бехчета, узелковый полиартериит. Вышеуказанные патологии очень часто сопровождаются развитием сосудистых пораже- ний головного мозга преимущественно у лиц молодого возраста, приводя к формированию как острых, так и хронических нарушений мозгового кровообращения. Р3 сопровождаются васкулитами и/или васкулопатиями церебральных сосудов. Следует отметить, что неврологические синдромы включены в классификационные критерии системных васкулитов. Неврологические нарушения при Р3 требуют проведения дифференциальной диагностики и назначения адекватного лечения совместно ревматологом и неврологом [3].

Патология нервной системы при ревматических заболеваниях имеет следующие особенности [4]:

- разнообразие клинической картины, обусловленное сочетанием неврологических и соматических нарушений, особенно при ревматическом поражении мышц и суставов;

- множественное и многоуровневое поражение нервной системы, с развитием моно- и полиневропатии, миелопатии и энцефалопатии, связанное с мультифокальным поражением головного мозга;

- высокая частота неврологических нарушений в молодом возрасте (у больных с СКВ и АФС первое нарушение мозгового кровообращения нередко возникает до 25 лет);

- наступление быстрого и значительного регресса острой неврологической симптоматики под влиянием ГК и цитостатиков и отсутствие такового при проведении традиционного неврологического лечения;

*e-mail: fidan_kasumova@hotmail.com 
- возможность частичного или полного регpecca неврологических и психических нарушений у больных с длительной ремиссией Р3 [4].

Нарушения со стороны нервной системы при P3 имеют различные проявления. Так, одним из наиболее известных поражений нервной системы при ревматоидном артрите (РА) является периферическая полиневропатия, при которой поражаются как двигательные (моторные), так и чувствительные (сенсорные) волокна, выявляемая более чем в 50\% случаев [5]. У больных развиваются парестезии, чувство жжения в области нижних и верхних конечностей, снижается тактильная и болевая чувствительность. Полиневропатия характерна больше при длительном течении ревматоидного артрита [6].

Другой формой поражения периферической нервной системы при РА является компрессионная невропатия (синдром запястного канала, тарзального канала и т.д.), вызванная сдавлением периферических нервных стволов или их сосудистым поражением. Это и создает симптомокомплекс туннельных синдромов [7]. Компрессия нервных стволов сопровождается болями в конечностях, парастезиями, онемением, регионарной атрофией мышц [8]. Васкулит лежит в основе множественного мононеврита (за счет поражения vasa nervorum), характеризующегося асимметричным вовлечением нервных стволов [9]. Однако, при РА возможна и симметричная периферическая нейропатия, которая проявляется чувствительными или чувствительно-двигательными нарушениями. При РА может развиться энцефалопатия, шейная миелопатия, васкулиты, вызывающие невропатию и инсульт, миозит и денервационная атрофия [10].

Нарушения со стороны вегетативной нервной системы проявляются гипер- или гипотермией, повышенным потоотделением, трофическими расстройствами [11].

С болезнью Шегрена, ассоциированны различные формы периферических нейропатий, включая сенсорную атаксическую нейропатию, болевую сенсорную нейропатию без сенситивной атаксии, нейропатию тройничного нерва, мононейропатии, множественные черепные нейропатии, радикулонейропатии и вегетативную нейропатию с ангидрозом $[12,13]$. У пациентов с жжением и парестезиями при сохраненной скорости проведения по нервам может быть нейропатия мелких волокон. У таких больных может отмечаться селективная потеря болевой (укол иглой) и температурной чувствительности (мелкие волокна) при нормальной вибрационной чувствительности и сохраненных рефлексах с глубоких сухожилий (крупные волокна) [14].

Поражение ЦНС при синдроме Шегрена проявляется васкулопатиями, которые могут привести к инсульту, менингиту, миелопатии, поражению по типу рассеянного склероза и дефектам V, VII, VIII черепных нервов. [15]. У больного синдромом Шегрена был описан продольный поперечный миелит (вовлечение $\geq 4$ сегментов позвонков) и оптический неврит, ассоциированные с антиаквапорин-4-антителами (оптический антинейромиелит) [16]. Этот синдром идентичен болезни Девика (оптический нейромиелит) и ассоциируется с анти-SSA/Ro- антителами. Возможны частые рецидивы заболевания. Исходя из этого, у каждого пациента с поперечным миелитом или оптическим невритом, необходимо исключать синдром Шегрена.

Неврологические нарушения при анкилозирующем спондилоартрите (AC) чаще всего проявляются в виде моно- и полинейропатии, радикулопатии, цервикокраниалгии, мортоновской метатарзалгии, синдромов метакарпального канала и канала Гуйона, невралгии тройничного нерва и неврита лицевого нерва $[17,18]$. Более редкая неврологическая проблема - синдром «конского хвоста», развивающийся вследствие компрессии нервных корешков конечных отделов спинного мозга. При этом нарушается иннервация нижних конечностей и мочевого пузыря, что приводит к нарушению тазовых функций, парезу ног [7, 19].

При АС в связи с выраженным остеопорозом, после незначительной травмы вследствие атлантоаксиальных подвывихов могут развиваться переломы шейных позвонков, с развитием квадриплегий [17]. Возможно развитие травматических переломов С5-С6 позвонков с развитием параплегий, признаки периферического мононеврита, оссификация задней продольной связ- 
ки со спинальным стенозом.

При злокачественном течении псориатического артрита у единичных больных неврологические проявления могут быть в виде невритов и полиневритов с двигательными и чувствительными нарушениями и энцефалопатии, с преимущественным вовлечением в процесс подкорковых образований, эпилептическими припадками и бредом. Данная форма всегда протекает при максимальной активности заболевания [20].

Нарушения со стороны нервной системы при системной красной волчанке (СКВ) (нейролюпус) наблюдается почти у всех больных и их симптомы очень многообразны. Спектр неврологических расстройств чрезвычайно широк от едва заметных невротических реакций до тяжело протекающего поперечного миелита [21, 22]. Неврологическая симптоматика при СКВ обусловлена васкулитами, тромбозами, инфарктами и геморрагиями в различных отделах головного мозга [3]. Важную роль в развитии неврологической симптоматики при нейролюпусе играет прямое поражение мозгового вещества антителами и отложение иммунных комплексов. Неврологические проявления, наблюдающиеся у пациентов с СКВ, можно определить со стороны центральной, периферической и автономной нервной системы [23, 24].

По данным различных авторов, нейропсихиатрические расстройства являются важными клиническими проявлениями при СКВ и частота встречаемости их составляет у 58-91\% пациентов. Наиболее частыми проявлениями вовлечения ЦНС являются головная боль, встречающаяся примерно у 57\% больных СКВ, когнитивные нарушения (21-52\%) и психиатрические нарушения (19-30\%), судорожный синдром (по типу височной эпилепсии) (17-37\%), нарушение функции черепно-мозговых нервов, мононейропатии, полинейропатии, нарушение мозгового кровообращения (вследствие тромбозов, геморрагии) $[25,26]$. Одним из наиболее серьезных осложнений нейролюпуса является ишемический инсульт, частота которого колеблется от $3 \%$ до $20 \%$ в первые пять лет после постановки диагноза СКВ [27, 28]. Острый поперечный миелит встречается редко и имеет неблагоприятный прогноз. [29].

Судороги - один из существенных критериев поражения ЦНС при СКВ и чаще ассоциируются с наличием антифосфосфолипидных антител (аФЛ). Рядом авторов описаны разные виды судорожных припадков при СКВ: большие, малые, по типу височной эпилепсии, а также гиперкинезы. При нейролюпусе имеет место головная боль типа мигрени, устойчивая к анальгетикам, но отвечающая на лечение глюкокортикостероидами $[25,26]$. Параличи черепных нервов обычно сопровождаются офтальмоплегией, мозжечковыми и пирамидными симптомами и нистагмом. Могут иметь место зрительные нарушения, преходящие нарушения мозгового кровообращения [30,31]. Психические синдромы разнообразны и характеризуются аффективными, органическими мозговыми или шизофреноподобными проявлениями [3, 32].

В рамках СКВ был описан и антифосфолипидный синдром (АФС), включающий рецидивирующие артериальные или венозные тромбозы различной локализации. Выраженность клинической симптоматики зависит от калибра пораженного сосуда.

Артериальные тромбозы у больных АФС развиваются в различных органах, но чаще всего (50\% случаев) - в артериях мозга, что приводит к ишемическим инсультам, преходящим нарушениям мозгового кровообращения и сосудистой деменции [33].

Тромбозы вен и венозных синусов головного мозга при АФС развиваются не часто и составляют $3 \%$ [33]. Именно неврологические нарушения, обусловленные тромбозами, включены в диагностические критерии АФС.

Чаще всего тромбируются верхний сагиттальный и поперечный синусы мозга. Клиническая картина обычно представлена синдромом внутричерепной гипертензии: головная боль, головокружение, тошнота, рвота, снижение и двоение зрения, эпилептические припадки (редко), отек дисков зрительных нервов на глазном дне, повышение ликворного давления.

Наряду с этим, у многих больных с АФС имеются неврологические расстройства, обусловленные не тромбозами, а первичным, очевидно, иммунологически опосредованным пов- 
реждением вещества головного мозга. К ним относятся эпилептические припадки, хорееформные гиперкинезы, деменция, поперечный миелит, синдром, имитирующий рассеянный склероз, зрительная и периферическая невропатии и др. [33-35].

Неврологическая симптоматика при системной склеродермии (ССД) в значительной степени обусловлена сосудистыми и фиброзными изменениями соответствующих органов. Поражения периферической нервной системы протекают по типу полиневрита, радикулоневрита или мононеврита, причем двигательные расстройства встречаются редко [36, 37]. Полиневритический синдром может быть связан с феноменом Рейно или первичным поражением периферических нервов. У 10\% больных может возникнуть тригеминальная сенсорная невропатия, проявляющаяся одно- или двусторонним онемением лица, часто сопровождающаяся болью или парастезиями. У пациентов с диффузной формой ССД часто развивается синдром запястного канала [7].

Центральная нервная система при ССД поражается сравнительно редко и связана в основном с наличием сосудистой патологии: вазоспазма и органического изменения мозговых сосудов. У таких пациентов отмечались судороги, головная боль, поражение черепных нервов, гемипарез, когнитивные расстройства и нервнопсихические расстройства [36, 37]. В отдельных случаях встречаются энцефалиты и менингиты. Хроническая неврологическая симптоматика развивается постепенно, сперва больных беспокоит головная боль, чувство тяжести, шум в ушах, снижение памяти. Затем развиваются оболочечно-корковый синдром с преобладанием фиброзно-склеротических изменений, клинически проявляющихся как тяжелый атеросклероз сосудов головного мозга [29].

У больных ССД возможно развитие и психических расстройств. Психопатологическая симптоматика выражается в виде тревоги, депрессии, обсессивно-компульсивных расстройств, склонности к соматизации. Несколько реже встречаются когнитивные нарушения и психотическая симптоматика, однако их распространенность выше, чем у здоровых людей [7].
Поражение нервной системы при дерматомиозите (ДМ) или полимиозите (ПМ) характеризуется развитием псевдоневрологической симптоматики, хотя у отдельных больных возможно развитие нерезко выраженного полиневрита и даже поражений ЦНС за счёт васкулита. Наиболее часто отмечаются вегетативные расстройства [38].

Неврологический статус при поражении ЦНС может был представлен рефлекторно-пирамидным синдромом с гиперефлексией сухожильных рефлексов, расширением рефлексогенной зоны и патологическими рефлексами, сочетанием поражения черепно-мозговых нервов (симптомы орального автоматизма, повышение мандибулярного рефлекса) и рефлекторной пирамидной симптоматикой.

Поражение периферической нервной системы при ПМ и ДМ проявляются болями корешкового или невралгического характера, которые часто сочетаются с миалгиями и сопровождаются болезненностью паравертебральных точек, по ходу периферических нервов, положительными симптомами натяжения и иррадиацией. У больных могут отмечаться корешковые боли шейно-плечевой и пояснично-крестцовой локализации. Полиневритические расстройства в дистальных отделах верхних и нижних конечностей могут проявляться в виде гипестезий, поверхностной чувствительности или гиперестезии с гиперпатией, а также гипо- или арефлексий [39].

Как известно, системные васкулиты - это группа иммунновоспалительных заболеваний, в основе патогенеза которых лежит воспаления в сосудах различного калибра, от аорты, до капилляров и вен. Клинически это выражается обширной неврологической симптоматикой, а также, изменениями со стороны ЦНС и периферической нервной системы.

Поражение нервной системы при болезни Такаясу обусловлено воспалительным процессом в брахиоцефальном стволе с вовлечением в патологический процесс общих сонных и позвоночной артерий, что и вызывает неврологическую симптоматику [40]. Больных беспокоят головные боли, головокружения, ухудшение памяти, внимания и работоспособности, пере- 
межающая хромота, пошатывание при ходьбе, часто бывают обморочные состояния. Появляется также объективная очаговая симптоматика, обусловленная ишемией общей сонной артерии соответствующего отдела ЦНС [41, 42].

Поражение артерий верхних конечностей, проявляется такими симптомами, как слабость и боли в руках, чувство онемения, нарастающее при физической нагрузке. Иногда появляются боли в области левой половины грудной клетки, левого плеча, шеи. Пораженные артерии болезненны при пальпации. На поздних этапах заболевания, в результате хронической ишемии восходящей или нисходящей части аорты или ее основных ветвей, у больных может возникать инсульт, развиться преходящая слепота, монокулярная слепота, атрофия зрительного нерва и помутнение роговицы [43].

Симптомы поражения нервной системы при гранулематозе Вегенера развиваются в более поздние сроки примерно у 20\% пациентов. Поражение периферической нервной системы проявляется множественным мононевритом, реже - симметричной периферической полинейропатией. Поражение ЦНС встречается реже и проявляется эпилептиформным синдромом и энцефалитом. При этом васкулите возможны развитие инсульта и повреждение черепных нервов [44].

Неврологические осложнения при синдроме Черджа-Стросса в виде поражения периферической нервной системы встречаются в 60-85\% случаев [44]. Основные проявления: остро или подостро развивающиеся, прогрессирующие мононевропатии, множественные полиневропатии (как правило, асимметричные) [45, 46]. В основе поражения периферических нервов лежит инфильтрация эозинофилами, лимфоцитами vasa nervorum, а из черепно-мозговых нервов чаще всего поражается зрительный нерв. Приблизительно у каждого четвертого больного появляются признаки поражения ЦНС: от расстройств в эмоциональной сфере до геморрагического инсульта, инфаркта головного и спинного мозга, эпилептических явлений [47].

Узелковый полиартериит - это форма системного некротического васкулита, которая обычно сопровождается множественными нев- рологическими расстройствами. Поражение нервной системы при узелковом полиартериите часто манифестируется множественной мононевропатией (моторными и сенсорными нарушениями седалищного, большеберцового, малоберцового, срединного или локтевого нервов), а также множественным мононевритом и симметричной полинейропатией [48]. Периферические нервы могут поражаться один за другим. При этом почти постоянно наблюдаются сильные боли, нередко носящие стреляющий, жгучий, каузальгический характер, а также парестезии, иногда парезы. Боли резко усиливаются при давлении на мышцы конечностей и нервные стволы. Проявляется развитием асимметричного моно- или полиневрита [49]. В основном поражаются нижние конечности. Иногда развивается дистальная сенсомоторная полиневропатия и позднее вовлечение ЦНС, приводит к развитию энцефалопатий [10]

При вовлечении в патологический процесс ЦНС у больных отмечаются головные боли. В некоторых случаях может развиться картина ишемических или геморрагических инсультов, полимиелорадикулоневрита с парезом кистей и стоп.

Поражение нервной системы является тяжелым проявлением болезни Бехчета и развивается у $38 \%$ больных, чаще в молодом возрасте [7]. Неврологические симптомы диагностируются в первые 5 лет после клинической манифестации заболевания [50]. При болезни Бехчета выделяют 2 основных типа повреждения ЦНС:

- Паренхиматозное повреждение, в основе которого лежит диссеминированный менингоэнцефалит, связанный с васкулитом мелких сосудов.

- Непаренхиматозное повреждение обусловлено тромбозом венозных синусов мозга.

При болезни Бехчета возникает широкий спектр неврологических проявлений (нейроБехчет) - головные боли, инсульт, глазные и другие параличи черепных нервов, судороги, цереброваскулярная недостаточность, синдром ствола головного мозга, приводящий к мозжечковой атаксии и псевдобульбарному параличу $[51,52]$. Когнитивные нарушения манифистируют в виде нарушения исполнительных функций, ухудше- 
ние памяти, личностных изменений (апатия и др.), деменции [50]. Также встречаются заболевания спинного мозга, поражения полушарий и менингоэнцефалит.

При МРТ исследовании очаги поражения обычно располагаются в области срединностволовых структур и часто имеют небольшие размеры. Очаговые изменения выявляются у 70\% больных.

Таким образом, высокий удельный вес неврологической патологии при различных нозологических формах Р3, диктует необходимость более

\section{ЛИТЕРАТУРА - ӘDӘВIYYYAT - REFERENCES}

1. Аджигайтканова С.К. Диагностика и лечение отдельных форм ревматических заболеваний с позиции доказательной медицины. Учебно-методическое пособие. М. ГБОУ ВПО РНИМУ им. Н.И. Пирогова, 2013; 52 с.

2. Раскина Т.А., Семенов В.А., Королева М.В., Летаева М.В. Неврологические проявления системных ревматических заболеваний. Возможности фармакологической коррекции // Современная ревматология, 2011; №4: с.61-65

3. Шилкина Н.П., Спирин Н.Н., Дряженкова И.В. Диагностика и лечение поражений нервной системы при ревматических заболеваниях // Лечащий врач, 2009; № 4: C.26-29.

4. Грачев Ю.В. Нейроревматология - междисциплинарное клиническое направление. Характеристика и классификация неврологических проявлений системных ревматических заболеваний // Нейронауки, 2005;1:54-57.

5. Филатова Е.С., Эрдес Ш.Ф. Полиневропатия при ревматоидном артрите: значение в патогенезе болевого синдрома // РМЖ, 2017; №7: с. 470-473.

6. Ramos-Remus C., Duran-Barragan S., Castillo-Ortiz J.D. Beyond the joints. Neurological involvment in rheumatoid arthritis // Clin. Rheumatol., 2012; Vol. 31. P. 1-12.

7. Бадокин В.В. Ревматология. Клинические лекции/Под ред. Проф. В.В. Бадокина / М.: Литтерра, 2014; 592 с.

8. Саковец Т.Г., Богданова Э.И. Поражение периферической нервной системы при ревматоидном артрите // Российский журнал боли, 2017; №1 (52): с.48-49.

9. Муравьев Ю.В. Внесуставные проявления ревматоидного артрита // Научно-практическая ревматология. 2018;56(3):356-362

10. Sofat N., Malik O., Higgens C.S. Neurological involvement in patients with rheumatic disease // QJM: An International Journal of Medicine, 2006; Vol. 99, p. 69-79. doi.org/10.1093/qjmed/hcl005.

11. Мазуров В.И. Клиническая ревматология (руководство для врачей). Санкт-Петербург: ООО Издательство «Фолиант», 2005; 520

12. Саковец Т.Г. Клинические особенности поражения нервной системы у пациентов с болезнью Шегрена // Практическая медицина, 2017; ․№8 (109): с.122-125.

13. Vitale C., Palombi G., Cataleta P. Treating Sjogren's syn- углубленного изучения цереброваскулярных и других неврологических нарушений при данной группе заболеваний. Учитывая вышесказанное, больные Р3 должны проходить комплексное клинико-инструментальное неврологическое исследование уже на ранней стадии патологического процесса. Своевременное выявление неврологической симптоматики при РЗ и комплексная терапия глюкокортикостероидами и иммуносупрессантами будет способствовать коррекции нарушений со стороны нервной системы при данных патологиях.

drome: insights for the clinician // Ther. Adv. Musculoskelet. Dis., 2010; №2: P. 155-166.

14. Вест С. Дж. Секреты ревматологии: Пер. с англ. - М.: «Издательство ГЭОТАР-Медиа», 2018, с.188-194.

15. Michel L., Toulgoat F., Desal H. et al. Atypical neurologic complications in patients with primary sjögren's syndrome: report of 4 oases // Semin. Arthritis Rheum., 2011; №40: P. 338-342.

16. Berkowitz A. L., Samuels A.L. The neurology of Sjogren's syndrome and the rheumatology of peripheral neuropathy and myelitis // Pract. Neurol., 2014; Vol. 14, № 1: p. 14-22.

17. Антонова Л.Н. Поражение периферической нервной системы при анкилозирующем спондилите // Международный неврологический журнал, 2011; №7 (45): с.47-45.

18. Hanaoka B.Y. Peripheralmononeuropathy with etanerceptuse: case report/B.Y. Hanaoka, J. Libecco, M. Rensel, R.A. Hajj-Ali // J. Rheumatol., 2008; Vol. 35, № 1: P. 182-183 19. Khedr E.M., Rashad S.M., Hamed S.A., El-Zharaa F. Neurological complications of ankylosing spondylitis: neurophysiological assessment // Rheumatol. Int., 2009; Vol. 20, № 1: P. 50-55.

20. Алексеева Е.И., Бзарова Т.М., Фетисова А.Н., Валиева С.И., Слепцова Т.В., Исаева К.Б., Денисова Р.В., Митенко Е.В., Чистякова Е.Г. Опыт ведения пациента с тяжелым течением псориатического артрита // Вопросы современной педиатрии, 2013; 12 (3): 90-96.

21. Rahman A., Isenberg D.A. Systemic Lupus Erythematosus // New Engl J Med. 2008; 358: 929-939. Doi: 10.1056/NEJMra071297

22. Гарабова Н.И., Буржунова М.Г., Струценко А.А., Нежельская А.А., Иванова С.М Случай системной красной волчанки с неврологическими осложнениями // Трудный пациент, 2018; Том 15, №5: с.35-37.

23. Govoni M, Bortoluzzi A, Padovan M, et al. The diagnosis and clinical management of the neuropsychiatric manifestations of lupus // J. Autoimmun., 2016;74:41-72.

24. Jafri K, Patterson SL, Lanata C. Central nervous system manifestations of systemic lupus erythematosus // Rheum Dis Clin North Am. 2017;43:531-545.

25. Файзулина Д.Л., Шпрах В.В. Поражение нервной системы при системной красной волчанке // Сибирский 
медицинский журнал. 2009; 7: с. 5-9.

26. Toubi E., Kessel A., Bamberger E., Golan T.D. Systemic Lupus Erythematosus Vasculitis: A Current Therapeutic Overview. Curr Treat Opt Card Med. 2004; 6 (2): 87-97.

27. Alair Sarmet Santos Neuroimaging in rheumatic diseases // Radiol. Bras., 2018; 51(4): p. 9-10. doi: 10.1590/01003984.2018.51.4e2.

28. De Amorim LC, Maia FM, Rodrigues CE, et al. Stroke in systemic lupus erythematosus and antiphospholipid syndrome: risk factors, clinical manifestations, neuroimaging, and treatment // Lupus, 2017;26:529-536.

29. Визир В.А., Буряк В.В., Шолох С.Г., Заика И.В., Полякова А.В. Основы диагностики, лечения и профилактики заболеваний костно-мышечной системы и соединительной ткани. Часть 2. Учебно-методическое пособие для аудиторной и внеаудиторной работы студентов 5 курса. - Запорожье, ЗГМУ, 2017; 128 с.

30. Budhoo A, Mody GM. The spectrum of posterior reversible encephalopathy in systemic lupus erythematosus. Clin Rheumatol. 2015;34:2127-34.

31. Dhillon A, Velazquez C, Siva C. Rheumatologic diseases and posterior reversible encephalopathy syndrome: two case reports and review of the literature. Rheumatol Int. 2012;32:3707-13.

32. Лисицина Т.А., Вельтищев Д.Ю., Серавина О.Ф. и др. Варианты психических нарушений у больных системной красной волчанкой // Научно-практ. ревматол., 2008; 4: 21-27.

33. Калашникова Л.А. Цереброваскулярные нарушения при антифосфолипидном синдроме // Анналы клинической и экспериментальной неврологии, 2011; Том 5. № 1: c. $39-43$.

34. Калашникова Л.А. Первичный антифосфолипидный синдром и нарушения мозгового кровообращения // Журнал неврологии и психиатрии им. С.С. Корсакова 2005; 105 (5): 11-16.

35. Rodrigues C.E.M., Carvalho J.F., Shoenfeld Y. Neurological manifestations of antiphospholipid syndrome // Eur. J. Clin. Invest 2010; 40: 350-359.

36. Amaral TN, Peres FA, Lapa AT, et al. Neurologic involvement in scleroderma: a systematic review // Semin Arthritis Rheum. 2013;43:335-47.

37. Pinho J, Rocha J, Sousa F, et al. Localized scleroderma en coup de sabre in the neurology clinic // Mult Scler Relat Disord. 2016;8:96-8.

38. Григорова И.А., Сало В.И., Самойлова А.П., Гирька Ю.С., Салуа Агуми, Неврологические проблемы полимиозита - дерматомиозита // Международный медицинский журнал, 2010, № 4: с. 34-38.
39. Алексеева Т.М., Жулев Н.М., Карпцова Е.В., Сайкова Л.А. Критерии диагностики и комплексная терапия дерматомиозита и полимиозита // Вестник СанктПетербургского Университета, 2007; серия 11, №3: с.

40. Покровский А.В., Зотиков А.Е., Юдин В.Л. Диагностика и лечение неспецифического аортоартериита, М.: Ирис, 2002; 144 с.

41. Савченко В.А. Эпонимические термины в кардиологии (Eponymic terms in cardiology) [in Rusian] // Zaporozhskiy Meditsinskiy Zhurnal. 2015; 5(36):56-57.

42. Абсеитова С.Р., Чувакова Э.К., Сарсенгалиев Т.И., Криворучко Н.А.3, Абдижами Б.А., Молдажанова А.М. Неспецифическии аортоартериит с поражением левой ветви легочной артерии (Болезнь Такаясу) // Клиническая медицина Казахстана, 2018, 1(47):44-48 DOI: 10.23950/1812-2892-JCMK-00539].

43. David S. Younger Vasculitis of the nervous system // Curr Opin Neurol, 2004; 17(3):317-336. doi: 10.1097/00019052200406000-00014.

44. Крутько В.С., Потейко П.И., Ходош Э.М. Гранулематоз Вегенера (распространённость, причина, диагностика, собственные наблюдения) // Новости медицины и фармации, 2015; (530): 63-72.

45. Исайкин А.И., Черненко О.А., Пожидаев К.А., Смирнова Д.С., Ильина К.А. Поражение периферической и центральной нервной системы при синдроме ЧерджаСтросс (эозинофильном гранулематозе с полиангиитом) // Неврологический журнал 2017; 22 (5): 267-274. DOI: http://dx.doi.org /10.18821 /1560-9545-2017-22-5-267-274.

46. Vaglio A., Buzio C., Zwerina J. Eosinophilic granulomatosis with polyangiitis (Churg-Strauss): state of the art // Allergy, 2013; 68(3): 261-273.

47. Савчук Е.А., Петров А.В., Иошина Н.Н., Кузина О.С., Овдей А.Г., Савчук О.М. Неврологические осложнения эозинофильного васкулита (клинический случай) // Крымский терапевтический журнал, 2015; №3: с. 69-73.

48. Pagnoux C, Guillevin L. Peripheral neuropathy in systemic vasculitides // Curr Opin Rheumatol 2005;17:41-48.

49. Hubert de Boysson, Loïc Guillevin Polyarteritis Nodosa Neurologic Manifestations // Neurol Clin., 2019 May;37(2):345-357. doi: 10.1016/j.ncl.2019. 01.007.

50. Пизова НВ. Когнитивные нарушения при распространенных и редких соматических заболеваниях // Неврология, нейропсихиатрия, психосоматика. 2015;7(3):86-92.

51. Uygunoglu U, Siva A. Behçet's syndrome and nervous system involvement // Curr Neurol Neurosci Rep. 2018;18:35. 52. Aguiar de Sousa D, Mestre T, Ferro JM. Cerebral venous thrombosis in Behçet's disease: a systematic review // J. Neurol. 2011;258:719-27. 


\title{
XÜLASə
}

\section{BəZI REVMATIK XəSTəLIKKLӘR ZAMANI NEVROLOJI POZUNTULARIN SPEKTRİ}

\author{
'Qasımova F.N., ${ }^{2}$ Oliyev R.R., 'Məmmədova R.N. \\ Ә. Đliyev adına Azarbaycan Dövlat Həkimlari Takmilloşdirma İnstitutu, 'terapiya kafedrası va \\ ${ }^{2}$ nevrologiya va klinik neyrofiziologiya kafedrasl, Bakl, Azarbaycan
}

Revmatik xəstəliklər (RX) - poliorqan zədələnməsi ilə xarakterizə olunan immun-iltihab1 xəstəliklər qrupudur. RXnin çoxunda pozuntular sistemli xarakter daşıyır və xəstələrin əksəriyyətində patoloji prosesə sinir sistemi də cəlb olunur. RX zamanı sinir sisteminin zədələnməsi mərkəzi və periferik sinir sistemi tərəfindən müxtəlif simptom və sindromlarla müşahidə olunur. RX-nin müxtəlif nozoloji formalarında nevroloji patologiyanın geniş diapazonu bu qrup xəstəliklər zamanı serebrovaskulyar və digər nevroloji pozuntuların daha dərin öyrənilməsinə eytiyac yaradır. Açar sözlər: revmatik xəstəliklər, nevroloji patologiya, mərkəzi və periferik sinir sistemin zədələnməsi.

\section{SUMMARY}

\section{THE SPECTRUM OF NEUROLOGICAL DISORDERS IN SOME RHEUMATIC DISEASES}

\section{${ }^{1}$ Gasimova F.N., ${ }^{2}$ Aliyev R.R., ${ }^{1}$ Mammadova R.N.}

Azerbaijan State Advanced Training Institute for Doctors named after A. Aliyev, 'Department of Therapy and 'Department of Neurology and Clinical Neurophysiology, Baku, Azerbaijan

Rheumatic diseases (RD) are a group of immunoinflammatory diseases characterized by multiple organ damage. Most RD have a systemic nature of the lesion, and in most patients, the nervous system is involved in the pathological process. Damage to the nervous system in RD is manifested by a variety of symptoms and syndromes from the central and peripheral nervous system. A wide range of neurological pathology in various nosological forms of $\mathrm{RD}$, dictates the need for a more in-depth study of cerebrovascular and other neurological disorders in this group of diseases.

Keywords: rheumatic diseases, neurological pathology, damage to the central and peripheral nervous system.

Redaksiyaya daxil olub: 08.07.2020

Çapa tövsiya olunub: 05.08.2020

Rayçi: professor R.K.Şiraliyeva 